Res Pública Revista de Historia de las Ideas Políticas

ISSN: $1131-558 \mathrm{X}$

http://dx.doi.org/10.5209/rpub.67171

\title{
Literatura y política, lengua e imperio, nombre y poder
}

\author{
César López Rodríguez \\ Recibido: 01 de enero de 2020 / Aceptado: 22 de junio de 2020
}

Resumen. Se trata de producir una inquisición histórica que, ajena a las teorías del origen, produzca una comprensión provisional de la aventada relación existente entre lengua e imperio desde su literatura y política precisamente. En un paralelo constitucional y literario, se convocan y desmiembran una serie de textos nucleares fundamentales para el esclarecimiento de este fin. Se procura dar con la forma lingüística de la Monarquía Católica. Bajo forma de contraste, se favorece una conclusión que dé con la torsión del estilo en la transformación monárquica.

Palabras clave: lengua; estilo; imperio; nación; constitución.

\section{[en] Literature and Politics, Language and Empire, Name and Power}

Abstract. The aim of the work is to produce a provisory historical inquiry about the popular connection between language and empire. The text hence discuses literary and political documents. The text tries to delimitate the linguistic form of the Catholic Monarchy. Finally, in the form of a contrast, the conclusion exposes the stylistic turn produced by the monarchical transformation.

Keywords: language; style; empire; nation; constitution

Sumario. 1. No hay en la historia canon. Qué nación tardía. Cuál extraño caso. 2. Núcleo, programa, problema. Lo dijo Grégoire. 3. Lengua e imperio. Malas compañías. Secuencia. 4. Alba de Nación: índice de ausencias. 5. Bibliografía.

Cómo citar: López Rodríguez, C. (2020). Literatura y política, lengua e imperio, nombre y poder. Res Pública. Revista de Historia de las Ideas Politicas, 23(1), 241-252.

\section{No hay en la historia canon. Qué nación tardía. Cuál extraño caso}

No hay en la historia canon. No hay figura prevalente. Tampoco salud, ni cuidado. No hay lo normal y lo corrupto. No cabe en ella salvación: cuanto incorpora es ya profano. Es, digamos, del orden del carácter. Si es que carácter se opone a destino ${ }^{3}$. "Una cosa es el destino, otra la historia. Sólo que, tradicionalmente, la teología y la filosofía de la historia se han empeñado en convertir, a base de razones tan abstrusas como interesadas, la historia en destino"4. Desconoce, pues, orden nómico, justicia debida. Ignora anterioridad / posterioridad, ambas sólo inscripciones cronológicas, que pretenden hacer del tiempo un espacio, de su inscripción una posición. Hay en la historia facticidad, sus restos, nuestro trabajo. Con la filosofía de la historia, dificultades.

De ahí el extraño caso de calificar algo (no se sabe todavía bien qué) como extraño caso. Y su inmediata comprensión, digamos, como problema. En efecto, el extraño caso es un problema. Cada cual tiene los suyos. El extraño caso toma aquí la forma de LMH: Lingua Monarchiae Hispaniae, en referencia a una acotación lingüístico-conceptual de otro caso político (Lingua Tertii Imperii $)^{5}$. Pero no es aquí que se va a resolver filosóficamente ${ }^{6}$. El problema ha de ser des-sublimado.

\footnotetext{
1 Al profesor Julio Pardos, bajo cuyo magisterio directo en el Máster en Filosofía de la Historia: Democracia y Orden Mundial de la Universidad Autónoma de Madrid, y en su asignatura homónima, Literatura y política, nació, hace ya tiempo, esta intervención hoy reconstruida. A él se debe el texto en el doble sentido que el término estrictamente acota: como el cumplimiento de un deber, pero también como la identificación de una deuda. De su buen oficio nace el que yo pueda alcanzar.

2 Universidad Autónoma de Madrid cesar.lopezr@uam.es

3 No es necesario invocar a W. Benjamin. Tampoco gratuito aludir a un lector suyo: cf. R. Sánchez Ferlosio, "Carácter y destino", Claves de la Razón Práctica 153, 2005, pp. 4-12.

$4 \quad$ F. Duque, "La lógica de la constitución / La constitución de la lógica", en J.A. Pardos et. al. (eds.), Historia en fragmentos. Estudios en homenaje a Pablo Fernández Albaladejo, Madrid, UAM Ediciones, 2017, pp. 833-846, p. 833.

5 Cf. V. Klemperer, LTI. La lengua del Tercer Reich. Apuntes de un filólogo, Barcelona, Minúscula, 2001. No implica la referencia una proyección anacrónica, ni pretende una comparación históricamente desfasada: se trata, tan sólo, de señalar la centralidad de la lengua y sus políticas para los asuntos de constituyencia.

6 De resolución ha habido intentos filosóficos. También intentonas políticas. Si es que pueden distinguirse.
} 
Ha de identificarse en él la posibilidad de una apropiación no metafísica. Incluso, si se me apura, no filosófica. Conviene darle espacio en el solo orden de la discusión histórica. No es poco. Es darle sitio ${ }^{7}$. Conviene relativizarlo, disminuir su estatuto siniestro (lo familiar nofamiliar), asociarlo así con otros. Cabe, en efecto, decir que participa de otros conjuntos que demandan comprensión. Sólo en cuanto no comprendidos, traumáticos. Por ejemplo, así un sintagma del que hay un cierto uso: La nación tardia ${ }^{8}$. Y caben otros.

¿Viene de $L M H$ nación tardía? Sólo si cabe hablar de España antes de España. Pero no interesa aquí cuestión de origen. Sí, sin embargo, sola cuestión de nación. Se verá. ¿Qué hay de ésta?, ¿qué de su conexión?, ¿cuál la forma que vincula ambas expresiones? Una misma evaluación comparativa parece ahí ejercerse. O quizás no tanto. Pues objeto de historia ha de ser una singularidad. Estricto acontecimiento, y trama de éstos. Nada menos extraño, pues, que una singularidad extrema, ajena en todo punto a norma de comparación. Nada asimismo menos nacional que una nación tardía. Ambas categorías se presentan exentas de toda explicación posible. Pero no así de comprensión probable. Este texto procura, en la conexión de ambas, ejercer un ensayo histórico de comprensión. Patrocina entonces un orden provisorio de conexión entre las mismas: Nación tardía / LMH, ambas un extraño caso $^{9}$, cada cual singularidad extrema.

"«Sitio» es un término tan ambiguo como el de «historia», al que -según la convención del título de esta Presentación [i.e., Latencia espacial del pasado, nótese, no del tiempo]- se refiere y califica. En él confluyen -y quizá no se trate de una mera homonimia - tanto el situs, el lugar o asentamiento en y por el que algo es lo que es: su raíz o suelo, como la obsidio, la asechanza o el asedio que pone en peligro la existencia de algo", F. Duque, El sitio de la historia, Madrid, Akal, 1995, p. 10. Suficiente. Suficiente este punto de intersección vida / muerte (o, sujeción de -o $a$ - la vida / trance existencial) en el mismo sitio. Ese punto (de intersección) es el presente. En el tema hay problemas. Estos problemas son nuestros. Pues el presente es anómalo, hoy emergen.

La referencia de cuño y origen viene ahora completada. Cf. J.L. Villacañas, "Epílogo. La nación tardía y nosotros. El sentido de un concepto", en H. Plessner, La nación tardía, Madrid, Biblioteca Nueva, 2017, pp. 209-238. Interesa aquí especialmente lo concerniente al núcleo del diagnóstico: "España es una singularidad insuperable", p. 223.

9 Hay más, otros, viejos y nuevos. Aquéllos ya en actualidad no nos conciernen. Lo harían si fuéramos europeos, esto es, cristianos, esto es, romanos. No lo somos. Ya no. No nosotros. Y aquí estamos, quizás porque otros anteriores lo fueron. Esta relación sí atañe a nuestro tema, y así a nuestros problemas.

Se ha dicho, en efecto: "La función fabuladora ha ascendido desde la generación biológicamente útil de ficciones hasta una creación de dioses y mitos, y por fin se ha desprendido totalmente del mundo religioso para convertirse en libre juego. [...] De esa función fabuladora surgieron la epopeya de Gilgamesh y el mito de la serpiente del paraíso, la Ilíada y la leyenda de Edipo, la Comedia divina de Dante y la humana de Balzac; es raíz y fuente inagotable de toda gran creación literaria. [...] Es el trasfondo, el horizonte definitivo del complejo de la literatura europea. Teniendo en cuenta esto, comprenderemos a Europa en un sentido no espacial, sino histórico. La «europeización del cuadro histórico», tan necesaria hoy, debe aplicarse también a la literatura. Si Europa es una «formación» que participa de dos complejos culturales, el antiguo del Mediterráneo y el moderno de Occidente, lo mismo hay que decir de su literatura", E. Curtius, Literatura europea y Edad Media latina. 1, Madrid, FCE-España, 1999, p. 26. Y más: "Somos europeos cuando nos hemos convertido en ciues Romani", ibidem, p. 30. Ello atañe directamente a lo que el autor ha denominado el productivo "«Retraso» cultural de España", E. Curtius, Literatura europea y Edad Media latina. 2, Madrid, FCE-

\section{Núcleo, programa, problema. Lo dijo Grégoire}

Y singularidad extremada, en efecto, en la medida en que ambas toman cuerpo en cuanto tales, esto es, frente a la diferencia, sobre lo desigual. Ambos son nombres singulares. ¿Qué nación, pues? ¿Qué lengua? Aún: ¿qué lenguaje literario? De ambas: ¿qué literatura y política? De todo el conjunto mencionado: ¿cuál su común estilo? Cuestiones todas ellas del núcleo del tema o problemas.

¿Qué nación tardía? Digámoslo pronto (hoy puede decirse): España.

¿Qué Lingua Monarchiae Hispaniae? Comienzan las dificultades. ¿Cuál la conexión? Identidad no la hay, bien que pretenden lo contrario. Origen, ya se ha dicho, tampoco. No cabe en esta investigación. Más problemas trae este $\operatorname{sintagma}^{10}$. Hasta donde sé, no se han tematizado explícitamente, si bien siempre han subyacido a toda ulterior exposición. Toda ocupación de este asunto ha gravitado en torno al núcleo que este sintagma supone. $\mathrm{Su}$ centro es una suposición. Todo cuanto puede hacerse es en un cierto sentido sacar a la luz la entraña de ésta. $\mathrm{Su}$ suposición es, en efecto, un problema de traducción. $\mathrm{O}$, mejor, de traducibilidad. Y sus consecuencias.

Que Hispaniae no es España ya se sabe y se sabrá ${ }^{11}$. No es ése ahora el punto. Atañe el problema a la totalidad del sintagma. Vayamos, pues, por partes. Lingua - Lengua - Monarchiae - de la Monarquía - Hispaniae - de (digamos) España. Luego Lingua Monarchiae Hispaniae como Lengua de la Monarquía de España. Hay una relación genitiva. Hay, pues, una relación de posesión, en tres estratos superpuestos. No es el problema el sujeto nominal del sintagma. Lo es el sujeto histórico de la relación de posesión. Lo es la cualidad del genitivo así ejercido. Está bien traído, el nombre. En efecto, la lengua se predica de la Monarquía. La Monarquía de España. Si dividiéramos lógicamente el enunciado, tendríamos, con ello, condiciones de una relación de transitividad. En el sentido de: "Si la lengua es de la Monarquía / Y la Monarquía es de España / Entonces la lengua es de España". Conviene atender al despliegue de dicho núcleo temático, y atender al cuerpo (textual) que su curso histórico produce. Sólo, en efecto, en virtud de la prevalencia de uno u otro de los segmentos proposicionales que $L M H$ encierra, en virtud, pues, de la hegemonía de uno u otro de los nombres que en las relaciones de posesión de dicho núcleo prevalecen,

España, 1999, pp. 753-756. Se perfila una cierta vía muerta. También un problema de mímesis.

Reflexiones adyacentes a la temática del caso y la excepción, en su declinación hispana, en conexión también con la tachadura de las asechanzas de una Filosofía de la Historia posible o siempre amenazante (Filosoffa de la Historia) pueden encontrarse en C. López Rodríguez, Economía de la gracia. Constitución de Monarquía. Integración de Trento. Extraño caso católico, Cantoblanco, Ediciones de la Universidad Autónoma de Madrid, 2020, disponible en: https://libros.uam. es $/$ ?press $=$ tfm \&page $=$ catalog \&op $=$ view \&path $\% 5 B \% 5 \mathrm{D}=928 \&$ path $\% 5 \mathrm{~B} \% 5 \mathrm{D}=1649 \&$ path $\% 5 \mathrm{~B} \% 5 \mathrm{D}=1632-1$.

10 Por mucho que provenga de una analogía, o de la relación de textos con textos, por mucho que constituya una provocación. Otros envites no han faltado, consolidando el juego: cf. F. Vélez, "Desflorada lengua (Entrada a la LMH)", Despalabro. Ensayos de humanidades 4, 2010, S 115-S 119.

11 Cf. C. López Rodríguez, “Constitución de Nación, perdurado Imperio? Todavía Monarquía. Políticas de la reflexión en el primer constitucionalismo español”, Eikasia: revista de filosofía 83, 2018, pp. $29-65$. 
puede darse cuenta de la amplitud del tema, de la consistencia de su composición y de su actualidad misma. Pues la relación la corona España. Pero la funda la lengua. Ambos nombres son índice del comienzo y fin del período que nos ocupa. Y, en medio, Monarquía. Las tres mutuamente se acompañan. Ello es literatura y política. $\mathrm{O}$, mejor, lengua-lenguaje literario, o, incluso, estilo (a medio camino entre lengua / literatura) y su paralelo curso político. Pero también su intersección. Luego ha de haber una curva, una crisis de su devenir paralelo, un cruce entre ambos cursos históricos así distinguidos. La decisión sobre la lengua de su fundación es aquí el punto. Y así la pulsión de proliferación (e inutilidad, y descomposición) de la misma lengua en el momento de su solo cénit político. De ahí declina el curso (ya compuesto) a la propia desagregación de la Monarquía misma, emergiendo, en efecto, el momento nacional. Dicha terna testimonia, pues, desenvuelta, lo que en $L M H$ se encierra, a saber, como dijera el prof. Julio Pardos, un límite (también conector) entre literatura e Imperio.

Que este momento nacional traiga de suyo una decisión política existencial fundamental sobre $s u$ lengua no puede ser novedad. En efecto, lo dijo Grégoire. Lo exigió. Lo hizo explícito. Afirmó cómo el caso francés era canon para Europa. Veremos cómo operó ello en el caso hispano, o, cabe decir, ahora sí, español. Pues sólo de su fractura hispánica emergió su especificidad española. Así se ejerció en 1812 (cf. sec. 4). Veremos su específica impoliticidad: en su alba de nación su índice de ausencias. Veremos su desocupación temática de lengua, lo cual es ya índice de la instauración o victoria de una lengua de España. Y, por tanto, una decisión, siquiera por la vía de los hechos, de la forma lingüística de su materia. Pero hay otros momentos, previos. También otros posteriores, a los que por restricción no alcanza esta encuesta (así, por último, la reorganización territorial o 1833). De ahí en adelante, toda lucha es, digamos, una lucha presente. El esquema está dispuesto: hay una evidente relación entre Constitución y lengua nacional. Lo demuestra el caso francés. Desde ahí se manifiesta un juicio también sobre las cosas de España. Y de sus orígenes. La pluralidad de éstos denota, ya se ha dicho, su estatuto defectivo en cuanto tales. Pero ahora conviene ocuparse del síntoma que el abad, en su texto, es o constituye. De su diagnóstico (dicho) terminal de la $L M H$, siquiera en el momento borbónico de torsión en imperial turn. Y también del índice que, en cuanto a ello, el mismo texto evidencia, y de su estatuto político factor.

La Revolución, es sabido, introduce el vocabulario universal de los derechos. Antes lo hizo el pueblo americano, en su refracción mutua y asociación de independencia (1776). Pero Francia incorporaba un nuevo status. Allí había una más antigua historia. Otro cruce de costumbres, jurisdicciones, parlamentos: otra multiplicidad de lenguas. De ahí la inoperatividad de un texto como el Grégoire en el caso estadounidense. Y su necesidad en el caso franco. En efecto, no otro es su título, dado a la Convención Nacional de Instrucción Pública (1794), que: "Rapport sur la nécessité et les moyens d'anéantir les patois et d'universaliser l'usage de la langue française". Este informe, programa técnico-cientí- fico, constituye asimismo una decisión política. Pues ejerce una discriminación, y cumple así una asimetría. En efecto, su solo título lo indica. La universalización de la lengua nacional francesa sólo puede realizarse bajo la negación, anegación o aniquilación estricta, violenta, bajo la sola reducción a nada, esto es, en la destrucción de los así llamados patois. No se distinguen dialectos de patois. Sólo el francés es lengua, idioma nacional. El resto, excrecencia, adición, escoria. Como la lengua que procura invocarse, construirse y conocerse, así se dice, al inicio, de la República, que es "une et indivisible"12.

Pero como análogo a nuestro tema o problema, se hace al inicio un juicio de radio europeo. Y cuyo contenido es, sin embargo, defectivo. Pues se busca un programa universal a escala francesa, esto es, un programa de unidad nacional. La Monarquía francesa, en cualquier caso, intervino en la división y reparto de la Monarquía de España. A tal momento regresa Grégoire. "La langue française a conquis l'estime de l'Europe, et depuis un siècle elle y est classique"13. Ha conquistado l'estime: conoce, en efecto, ejemplaridad externa, no universalidad interna. No ha conquistado Europa, sino su estima. $\mathrm{Su}$ hegemonía no es de armas. Tampoco en el interior de la Francia del momento. He ahí su estatuto fallido. El sujeto de este estatuto es "la France monarchique"14. Una nueva operación es, pues, requerida. No sólo es que se ignore el idioma nacional en Francia. Es que lo ignoran "une très grande partie des Français" 15 . Se pretende una arcaica unidad de lengua, coexistente asimismo con dialectos. Pero este equilibrio lo rompe la feudalidad. Por fraccionamiento. Todavía, pues, perdura, en la medida en que dichos dialectos se resistan a la negación por Constitución de Nación. "La féodalité, qui vint ensuite morceler ce beau pays, y conserva soigneusement cette disparité d'idiomes comme un moyen de reconnaître, de ressaisir les serfs fugitifs et de river leus chaînes. Actuellement enconre, l'éntendue territoriale où certains patois sont usités, est déterminée par les limites de l'anciene domination féodale"16. El dialecto es, pues dispositivo político, instrumento de sujeción a servidumbre. Muchos hay, todos dialectos de opresión. Una sola, sin embargo, es lengua de libertad: "Mais au moins on peut uniformer le langage d'une grande nation [...]. Cette entreprise, qui ne fut pleinement exécutée chez aucum

H. Grégoire, "Rapport sur la nécessité et les moyens d'anéantir les patois et d'universaliser l'usage de la langue française", en D. Julia, J. Revel y M. de Certeau, Une politique de la langue. La Révolution française et les patois: l'enquête de Grégoire, Paris, Gallimard, 2002 , pp. 300-317, p. 331. A título de localización institucional. Luego de nuevo en p. 334 como voluntad / prognosis (o prolepsis, dada la condición mixta técnico-política del texto: aquí voluntad es saber, desde entonces saber es poder).

3 Ibidem, p. 332.

14 Idem. También en su pulsión unificadora interna. Aunque aquí se trate de su defección. No es necesario en este punto acudir a la autoridad de R. Koselleck. Baste hacerlo a la de su maestro: "En la mayor parte de los Estados de Europa, la unidad política fue obra del absolutismo monárquico", C. Schmitt, Teoría de la Constitución, Madrid, Alianza, 2016, p. 90. En Francia hay un conato, no sin embargo suficiente. O no para Grégoire y otros revolucionarios.

H. Grégoire, op. cit., p. 332. Luego se nos dice que: "au moins six millions de Français, surtour dans les campagnes, ignorent la langue nationale", ibidem, p. 334.

6 Ibidem, p. 333. 
peuple, est digne du peuple français, qui centralise toutes les branches de l'organisation sociale et qui doit être jaloux de consacrer au plutôt, dans une République une et indivisible, l'usage unique et invariable de la langue de la liberté [s. mío]"17. Ello es la definición de Francia, toda vez que ésta sea Revolucionaria: la lengua es aquí la libertad. No hay Revolución de Constitución de Nación (caben aquí todos los quiasmos posibles) sin "identité de langage" 18 . Identidad dice aquí unidad, en la medida en que se realiza conforme a una operación: "fondre tous les citoyens dans la masse nationale" ${ }^{19}$. Una más exacta conexión entre Revolución / Constitución / Nación se hace luego explícita: "Je crois avoir établi que l'unité de l'idiome est une partie intégrante de la révolution"20.

Pero no todo es política en este informe revolucionario. Hay también arte, academia, disciplina. Y una estricta conciencia del estatuto normativo con que, a tales efectos, contaba históricamente el italiano. Casi todavía al ocaso del siglo. Y al inicio del siguiente. De esta comparativa, de este canon de excelencia que Italia representa en cuanto a los usos de lengua y estilo, aparece ausente España. Extraño caso éste, dada la reciente implicación de la Monarquía francesa en las cosas de aquélla. Al filo del 800 , sólo en una ocasión comparecen los españoles. Y lo hacen a propósito de su lengua en su literatura. La comparación ejercida se hace respecto de otros dialectos, no del propio francés. A éste, y a su implantación institucional, se reserva una estricta comparación ulterior respecto del italiano. Aquí sólo se dice, de algunos dialectos: "Par leurs richesses et leurs prosodies éclatantes, ils rivalisent avec la douceur de l'italien et la gravité de l'espagnol"21. Esto que se dice del idioma, se había dicho de los españoles (tambiên, a qué decirlo, desde Francia). Y así de su política. Es coextensivo a su literatura, en cuanto ésta se construye sobre dicho estilo. Conviene, pues, dar con la cifra de dicha gravedad, y saber si su estatuto fue una dignidad o un obstáculo. O quizás ambas cosas ${ }^{22}$. En este punto, toda política es cuestión de estilo. Y el estilo, cosa de lengua.

\section{Lengua e imperio. Malas compañías. Secuencia}

La propia época tematizó su unidad. Lo hizo la cultura. Lo hizo por virtud de su común matriz textual, y por

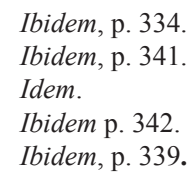

2 Ambigüedad esencial al tiempo que nos ocupa, explícitamente recogida por Covarrubias: "GRAVE, en una sinificacion vale autoridad y calidad, como persona grave. Caso grave, el que no es leve sino de mucha ponderacion y consideracion. Peso grave, el muy pesado, que no se puede buenamente llevar. Gravedad, autoridad ponderacion, mesura. Gravissimo, grave en sumo grado. Desagraviar, des hazer el agravio. Agraviado, el que ha recebido agravio e injuria. Desagraviarse, satisfacerse", S. de Covarrubias, Tesoro de la lengua castellana o española, Madrid, Luis Sanchez, 1611, p. 449. Más, a propósito de la secuencia humoral orgullo - gravedad - pereza, en P. Fernández Albaladejo, "Entre la «gravedad» y la «religión». Montesquieu y la «tutela» de la monarquía católica en el primer setecientos", en Materia de España. Cultura politica e identidad en la España moderna, Madrid, Marcial Pons, 2007, pp. 149-176. dicha refracción en la organización de sus estudios. Era fundamental en éstos un arte de la lengua. Así en el Trivium, compuesto en tres formas de estas artes: gramática, retórica, dialéctica. De allí al sistema de conformación y transmisión (que no transformación) del saber. $\mathrm{O}$, mejor, de los saberes. "Aquí viene la medicina. Constituía también una ciencia preceptiva. Vimos situarse en la Bibliotheca Hispana esta materia medica exacta y precisamente entre la theologica y la iuridica"23. La secuencia se cerrará con una misma relevancia de gramática. No sólo en cuanto disciplina. También en cuanto al contenido (nótese, de suyo un perfil) de una Gramática propia. Cada una de las artes, en efecto, con su latín. Ello funda una unidad en los saberes, pero también una oposición. Da cuenta de estas y otras cosas, y de su común y anfibológica referencia central a la curia, el primero de los textos hispanos capitales a este efecto. Firmado por un obispo. Naturalmente escrito en latín.

Hay en el texto de Alfonso de Cartagena, escrito ca. 1430, una inicial occasio (situada en 1427). "Al haberme llevado recientemente una embajada real hasta la región más occidental, insigne varón Fernando, y verme obligado por la magnitud de las ocupaciones, si recuerdas, a prolongar mi estancia allí, como el tiempo suele hacer, la dilación ya me había reportado una cierta notoriedad y algunos hombres instruidos de esa provincia se relacionaban conmigo cordialmente" ${ }^{24}$. Donde la traducción dice "región", al inicio, dice el original: "Ad ultimam occidentis prouinciam". Donde luego dice "provincia", así lo dice también en latín. Luego en el extremo del mundo no hay todavía Mundo Nuevo. Hay Portugal. O, mejor, Reino de Portugal. Allí cuenta el obispo de Burgos al rey Fernando cómo trabó relación con algunos hombres instruidos. Habiendo sido éstos estudiantes de Bolonia, él en Salamanca. Ellos hablaban de sus maestros, "que habían sobresalido en jurisprudencia"25. Él entonces alababa a "algunos de nuestros mayores que cultivaron con gran ahínco la disciplina del derecho [maioribus nostris laudabam, qui iuridicam facultatem magno studio coluerunt], no porque queramos comparar a los nuestros con los italianos en cuanto a escritos, cuando no hay, sin duda, una proporción de igual a igual, sino porque en las actividades académicas y en los procesos de las causas [in scholasticis actibus ac in disceptationibus causarum] frecuentemente se han encontrado entre nosotros hombres decididos, los cuales si se hubieran consagrado con denuedo a una labor ininterrumpida, tal vez habrían escrito algo bueno como los demás"26.

Vemos que derecho no lo hay, no se le conoce. Derechos, menos todavía. Hay iuridicam facultatem y iurisprudencia. Por lo demás, se hace allí también explícita la bipartición fundamental de su régimen de saber (eludiendo a la medicina). Hay una división en virtud de textos, ambos cánones, uno anterior a otro, y de allí

\footnotetext{
B. Clavero, Antidora. Antropología católica de la economía moderna, Milano, Giuffrè Editore, 1991, p. 205.

24 A. de Cartagena, "Sigue el libro de Alfonso, obispo de Burgos", en T. González, A. Moreno, P. Saquero (eds.), Humanismo y teoría de la traducción en España e Italia en la primera mitad del siglo $\mathrm{XV}$, Madrid, Clásicas, 2000, pp. 194-264, p. 195.

26 Ibidem, pp. 195-197.
}

25 Idem. 
toda otra ulterior diferencia se deriva. Ambos regímenes devienen en relaciones curiales. De ahí el condicional invocado: "si se hubieran consagrado con denuedo...". Pero: "Pero aquí la costumbre [mos] se impuso ya desde la antigüedad misma, de forma que, del mismo modo que los italianos se ponen a escribir cuando empiezan a saber, así los nuestros se lanzan a la corte real [sic nostri in regiam curiam ruant], de ahí que aquéllos dirigen el mundo con la multiplicidad de sus libros [qup fit, ut et isti librorum warietate orbem torqueant], mientras éstos se conforman con la lectura de libros ajenos y se figuran que han hecho bastante con discutir las ocurrencias de los demás con exquisito ingenio"27. El diagnóstico está hecho. El problema, dado. No sólo, pues, lengua: en él interviene texto. No sólo se enuncia la centralidad del ingenio, también su inutilidad. A él se opone el dominio del orbe. Un dominio fáctico, y sin embargo no físico: orbem torqueant. Tuercen el mundo. Lo retuercen, lo aprietan como una soga. Lo hacen porque lo tienen en las manos. Y mediante los libros. Es la primera declaración, en nuestra secuencia, de la materialidad del lenguaje como factor político. Como, podríamos decir, medio de poder secundario. Todas las demás manifestaciones incidirán en esto. Frente a ello, jurisprudencia y teología son succionados por la corte. Alejados de su curso escolar normal, en este sentido desorbitados. La utilidad del saber es, pues, otra. Más directamente política se pretende, pero es sin embargo más políticamente arruinada.

"Mientras charlábamos asiduamente sobre estos asuntos y consagrábamos largas horas a discursos de semejante naturaleza, uno de los que se entregaban a la tarea de la elocuencia [qui eloquentiae operam dederant] ensalzó en este arte a un tal Leonardo Aretino, asegurando que estaba profundamente instruido [quendam Leonardm Aretinum in eloquentia extollebat], tanto en la lengua griega como en la latina"28. La hegemonía conceptual, ya se ve, es la de la eloquentia. Por lo demás, ella supone un trabajo, una específica operación. Un esfuerzo. No es natural a un idioma. Se produce en la ocupación de un texto. No es, en este punto, sólo saber latín. Es saber latín elegante. Practicar latín elocuente. La gramática que venga, deseada, será puesta sobre la elocuencia. Ahí está el ejemplo italiano, en relación con Aretino. No se dice, pero se comprende: no habla mejor latín, sino otro latín, uno operante, no lengua muerta. Lengua muerta es la que conoció Cartagena, inducida institucionalmente. Y deforme respecto del latín modernamente exhumado. Artificiosa. Así pues, lengua nacida muerta, construida artificialmente, a pesar de su uso cotidiano en política de curia. La oposición es, pues, elocuente / cotidiano.

Pero el texto es índice de un status académico-político. No factor de transformación. De ahí que, tras la comparación hispano-italiana en cuanto a regímenes de discurso, Cartagena se ocupe en deslegitimar una traducción de la Ética de Aristóteles, realizada desde el original griego. Un texto que vertió al latín. A un latín elocuente. Cartagena, desde su acervo teológico, discutió la

\footnotetext{
Ibidem, p. 197

28 Idem.
}

legitimidad de dicha traducción. Se veía autorizado en la medida en que fundaba su posición no en la discusión de verba, sino en la discusión de res. Por eso sin saber griego la enmienda. La historia que contamos es la de la subversión de esta prioridad. La de la mutación de un sistema político axialmente contrapuesto al italiano. Es la historia de la introducción de dicha elocuencia en los territorios de la Monarquía de España. Y su integración y rebasamiento.

Siguiente texto en nuestra secuencia, algo posterior, es de 1444. Mismo año, probablemente, en que nació Nebrija. Se hace en él explícita la centralidad de la retórica. Y la virtud política de una filiación cultural. Ya desde el mismo título: "LAVRENTII VALLENSIS PATRICII ROMANI COMMENTARIORVM GRAMMATICORVM SECVNDVM ELEGANTIAM LINGVAE LATINAE LIBER PRIMVS DE NOMINE VERBOQVE ET EX HIS DVOBVS COMPOSITO PARTICIPIO INCIPIT PROEMIUM"29, al margen, pues, de su estatuto técnico. Destaca ante todo que aquel contenido técnico sea expuesto mediante aquella "ELEGANTIAM LINGUAE LATINAE". Tal vínculo no hace más que explicitarse de inmediato: "Cuando reflexiono [cum saepe] sobre las hazañas de nuestros mayores y las de otros pueblos y reyes, me parece que nuestros hombres [nostri homines] superaron a todos los demás no sólo en la autoridad de la lengua, sino también en la propagación de la misma [linguae propagatione]"30. Cum saepe, retengámoslo. La figura comparecerá de nuevo. Ahora interesa más bien dar con el sujeto que enuncia este texto. Desde luego es Valla. Pero aquí el hombre singular se ve rebasado por una legitimidad mayor y anterior. No en vano dice de sí, en el título, "PATRICII ROMANI". En efecto, se señala aquí un vínculo con los romanos: nostri homines. Un vínculo de renacimiento. Y, al tiempo, el reconocimiento de su cualidad no sólo en cuando al dominio en elegancia de la lengua, sino también, y por lo mismo, en cuanto a su propagación política. Se reconoce como característica suya la extroversión, una vis expansiva. En este sentido, el texto de Valla quiebra la lógica de la translatio imperii / translatio studiorum, tal y como otro documento iniciático la traía ${ }^{31}$. No hay, en efecto, traslado. El imperio siempre ha estado allí. Ha subyacido a la

\footnotetext{
29 L. Valla, De linguae latinae elegantia, Cáceres, Universidad de Extremadura, 1999, p. 56.

$30 \quad$ Ibidem, p. 57.

31 Cf. La obertura del Cligès, relato de Chrétien de Troyes. De una versión en español: "Por los libros que tenemos conocemos los hechos de los antiguos y del mundo que fue antaño. Nuestros libros nos han enseñado que por primera vez se honró en Grecia la caballería y también la clerecía. Pasó luego la caballería a Roma y también lo mejor de la clerecía, que ahora han llegado a Francia. Quiera Dios que aquí se conserven y sean estimadas y que jamás salga de Francia la gloria que aquí se detuvo. Dios las había prestado a otros, pues ya no se habla ni poco ni mucho de los griegos y los romanos, ha cesado su palabra y su viva brasa se ha extinguido", Ch. de Troyes, Cligés, Madrid, Alianza, 1993, pp. 56-57. Por lo demás, la temática de la translatio imperii remite al libro de Daniel. Así también se refleja en el siguiente fragmento traído de Valla. Más sobre esta tópica en F. Vélez, "Translatio studiorum: Breve historia de la transmisión de los saberes", Mutatis Mutandis. Vol. 6, No. 1. 2013, pp. 126-138. Y cuyo complemento político puede hallarse en F. Vélez, "«Translatio imperii». Del mar de Dante al océano de Vázquez de Menchaca", Revista de Estudios Histórico-Jurídicos XXXV, 2013, pp. 783-797.
} 
lengua latina en su extroversión y elocuencia. Subyace todavía en el uso de su lengua.

"Perdimos Roma, perdimos el reino, perdimos el poder, pero no por nuestra culpa, sino por culpa de los tiempos; sin embargo, gracias a este poder tan espléndido de la lengua, reinamos todavía en una gran parte de la tierra. Nuestra es Italia, nuestra la Galia, nuestra Hispania, Germania, Panonia, Dalmacia, Iliria y otras muchas naciones, pues el Imperio romano está allí donde domina la lengua de Roma [Ibi namque Romanu imperium est, ebicunque Romana lingua dominatur]. Que vengan ahora, pues, los griegos y se jacten de la abundancia de lenguas. La nuestra por sí sola vale más [...] que las cinco suyas [s. mío]"32. Se tiene, así, una idea de dominio, un ideal de prevalencia. Veremos cómo explícitamente (bien que, como era uso, sin citarlo), un gramático se hace con él. Y lo invierte.

Pero antes hizo su camino en torno a estos temas. En efecto, Nebrija redactó unas Introductiones latinae en 1481. Las vertió luego al romance, por mandato regio, en unas Introduciones latinas en 1487. Nebrija estudió en Italia. Integró este bagaje. Lo hizo desde una específica incipiente conciencia histórica, frente a la continuidad pretendida en Valla. Nebrija conoce discontinuidades. Ello es ya conocer historia. Pues dedica tales primeras Introductiones a Pedro Mendoza, Cardenal, "como si de una novedad se tratara una materia ya hollada por gramáticos antiguos y modernos [quod rem ab antiquis et iunioribus grammaticis detritam]"33. Caminos, pues, anteriormente concurridos. Modernamente transitados. Los gramáticos intermedios (ahora puede ya conocerse tal tiempo, precisamente, en cuanto medio: medievo) no merecen tal nombre. Son nefastos. Han arruinado el latín. La operación del humanismo consiste en una depuración elocuente. Así también en este texto de Nebrija. Así él mismo lo enuncia: "Así que responderé que me ha sido permitido en la realización de esta obra lo que a los demás escritores de este arte [artis scriptoribus], quienes siguieron las huellas de los antiguos hasta un punto que no se apartaron de ellos ni el proverbial ancho de una uña [s. mío; referencia a Cicerón]"34.

Pero gramática dice norma. Dice adecuado uso de lengua latina. Uso elocuente. Ello sin embargo, en cuanto operación humanista, no es solucionable en solo sentido técnico. Se requiere otro tipo de norma: norma de textos, un cuerpo de tales. "Por mi parte, desde el momento en que comencé a profesar el arte de la gramática [artem grammaticam] nunca dejé de pensar qué autores debía enseñar y cuáles proponer como modelos a mis muchachos, siendo así que la gramática, según Quintiliano, en dos partes se gasta, una preceptiva a la que se denomina metódica y otra imitativa a la que se denomina histórica"35. El canon es también de autores. Ello es propiamente gramática. Se propone, pues, un canon de mímesis. La dificultad la constituye la mediación de va-

\footnotetext{
L. Valla, op. cit., p. 61 .

33 A. de Nebrija, Introductiones latinae, en "Paginae Nebrissenses", Gramática sobre la lengua castellana, Madrid, RAE-Galaxia Gutenberg, 2011, pp. 175-343, p. 180.

34 Idem. Igual intensa conciencia histórica acredita en el mismo lugar: "[...] nuestra época $[\ldots][$ vs.] aquel tiempo $[\ldots]$ ".

35 Idem.
}

rias distancias temporales. Aclarar la opacidad temporal de dicha mediación es lo que Nebrija procura.

Otros términos de apariencia moderna se emplean allí. Pero no lo son tanto. Son de suyo de matriz latina. No salimos del marco del latín. Tampoco en la política. Al propio Cardenal, le dice: "Pues fue muy justa la razón de dedicar a Vuestra Ilustrísima estas veladas mías. Y porque entre la gente de nuestra nación [in gente hac nostra] sois no sólo el prelado de las cosas sagradas, sino además defensor y como guardián de todas las buenas artes [bonarum artium]"36, etc. Pero nación es aquí imposible. No olvidemos que estamos en Introductiones. El texto original es latino. Allí se dice gente. Relativo, pues, al latino gentium, esto es, el sistema de relación del romano con el bárbaro, esto es, el no-romano. Entre romanos, media relación de ius civile. Para ser ciudadano romano bastaba tener dicho estatuto civil, se estuviera donde fuese. Hay así una transposición histórica. Inmediatamente se acentúa: "Y si a una señal vuestra de aprobación se me concederá superar a los enemigos de la lengua latina [latinae linguae hostes], a los que con la edición de esta obra acabo de declarar la guerra [bellum indixi]"37. Coexiste el interés del tiempo estrictamente presente en Nebrija con una filiación latina à la Valla. Ésta, sin embargo, no tardará en invertirse, reconstruyendo una nueva relación de herencia. Ya no, ciertamente, por participación presente, sino por innovada translatio imperii.

Un momento intermedio en esta progresión lo trae la versión castellana de las Introductiones, esto es, unas Introduciones latinas, dadas en 1487 "A la muy alta i muy esclarecida doña Isabel, la tercera deste nombre, Reyna i señora natural de España i las islas de Nuestro mar. Comiençan las Introduciones latinas del maestro Antonio de Nebrissa, contrapuesto el romance al latín, por mandado de su Alteza" 38 . Suficiente riqueza trae el texto romance como para vincularlo a la historia constitucional previamente ensayada. Esta es su fundamental valencia política: su estatuto como texto "mandado", frente al interés teórico-pedagógico autónomo que parecía guardar el anterior texto. En efecto, allí se dice mucho. De Isabel, "princesa". Ello nos trae ya el mismo recurso a la forma latina de concepción del poder. El texto es del 87. Ella, desde el 74, reina reinante. Pero quien ejerce en latín potestad es Princeps. Tercera de este nombre se dice, en efecto, por linaje (Trastámara). En cualquier caso, la referencia de orientación latina comienza a mutar. Hay ya una memoria gótica, pues al señorío de Isabel (no en vano "Reina i señora") se le dice "de España". Y no sólo "señora", esto es, que ejerce dominación (dominium), señorío, por decirlo en otro término constitucionalmedieval clásico: Herrschaft. Los nombres del poder se asocian, análogos. Sino también "señora natural", esto es, todavía en efecto no-moderna. Es Maquiavelo quien romperá la naturalidad del poder, construyendo un principe nuovo. Naturalidad dice aquí, además, no sólo

\footnotetext{
Ibidem, p. 182

Idem.

3 A. de Nebrija, Introduciones latinas, en "Paginae Nebrissenses", Gramática sobre la lengua castellana, Madrid, RAE-Galaxia Gutenberg, 2011, pp. 175-343, p. 199.
} 
referencia a la cualidad dinástica del poder, sino referencia a su territorio propio. De ahí la división, por yuxtaposición, de su título en cuanto señora natural " $i$ las islas de Nuestro mar [s. mío]”. La mayúscula evidencia pretensión de apropiación jurídica. Y asimismo reflejo de legitimidad romana. Es más "Nuestro" que "conocido". Todavía sólo han dado con las Canarias, décadas antes. Buscarán luego Indias. Hallarán Nuevo Mundo. Pero Nebrija no lo sabe. Ni siquiera ha salido Colón de Palos cuando se cierra el texto. Pero "natural", no cabe olvidarlo, se dice "de España": ello es memoria romana, ya se ha dicho, si bien mutada. También memoria gótica. España es aquí una licencia, una operación, como el caso anterior del Fuero General de Navarra también ilustra. España sólo cabe tras la explosión de Monarquía. Ni las Indias pasarán a formar parte de ésta. Ya se ha dicho: no hay España, o no España como reino. Serán de la Corona de Castilla. En cualquier caso, es de máximo relevancia que se pongan aquí las Introductiones como Introduciones, es decir, "contrapuesto el romance al latín, por mandado de su alteza". Romance era, en efecto, tanto un género poético tradicional como al tiempo palabra para designar genéricamente al vernáculo, fuera éste en concreto el que fuera. El romance, en cualquier caso, se contrapone al latín. Pero no lo sustituye. No alcanza tal dignidad. Es vehículo, instrumento de comprensión de la lengua digna (o gramática). Y es vehículo adecuado por dicha continuidad aludida. Hay aquí el núcleo de la relación dignitas - humanitas - romanitas. En ello no juega todavía el romance, ni menos todavía la hispanitas. Ya advendrá. Pero el romance no supone una ruptura respecto del latín. No es un post-latín. Es el latín dado por otros medios. En este sentido, es susceptible de apropiación gramática (desde la norma latina). En cualquier caso, por eso Nebrija no nombra al romance por su nombre propio, por eso no dice: "romance castellano".

Continúa el texto, de nuevo inscribiéndose en un régimen de saber, como en casos anteriores, y señalando así sus carencias o defectos. "Si los otros súbditos i casallos de Vuestra Real Magestad que han dado obra al estudio de las letras así miraron por el bien público $\mathrm{i}$ ornamento de nuestra España como yo [...] no menos sobraría nuestra nación a todas las otras en el conocimiento de las artes buenas i honestas que las sobra agora en todos los bienes que los hombres poseen por beneficio de la naturaleza i fortuna" ${ }^{39}$.

Ello es un juicio político. Naturaleza y fortuna son las dos categorías centrales que ordenan todo discurso sobre la política. Ambas presentan en cierta medida la condición de lo indisponible. De la naturaleza se participa. Se está sujeto a ella. A la fortuna también, sólo que esta adviene al margen de toda continuidad. De ahí que Nebrija exija un paralelo artístico (así también en cuanto a la gramática, arte al cabo) junto a la misma operatividad política que la Monarquía de España por entonces incipientemente realiza. Este beneficio aludido en la política lo es en grado sumo, debido a la condición indisponible del par dicho: beneficio es donación sin retribución, estricta gracia. No es teología. Es una categoría jurídica feudal.

39 Ibidem, pp. 199-200.
Luego viene lo que elude nombrando, o lo que callando dice: "Dexo [...] Dexo [...] No quiero [...] Callo $[\ldots]$ dexo $[\ldots]$ dexo $[\ldots]$ dexo" ${ }^{40}$. Deja lo que es condición ecfrática de España. Y, al fin, viene: "Vengo a lo qu'es proprio del ombre" 41 , esto es, humanitas. Pero esta humanitas es en cierta medida de Hispania. Se suceden los nombres latinos de dichas provincias. Lucano, Silio Itálico, Séneca, Valerio Marcial, Quintiliano, Gallión, Columela, Pomponio, Trogo. Y ello, ¿por qué lo trae? Él mismo lo pregunta: "Mas ¿a qué fin avemos traydoi tantas cosas en alabança [o género del laus] de nuestra España? Para demostrar lo que en el comienço diximos, que para el colmo de nuestra felicidad i complimiento de todos los bienes ninguna cosa nos falta sino el conocimiento de la lengua, en que está no solamnente fundada nuestra religión i republica christiana, mas aun el derecho civil i canónico, por el qual los ombres viven igualmente en esta gran compañía que llamamos ciudad: la medicina, por la qual se contiene nuestra salud i vida; el conocimiento de todas las artes que dizen «de humanidad», porque son proprias del ombre en cuanto ombre"42. Hay aquí un diagnóstico de la lengua latina. De sus carencias en territorios de Monarquía de España. De su utilidad también para este "imperio". De su necesidad en términos escatológicos, o de "felicidad i complimiento de todos los bienes". Emerge por primera vez, en asociación con ello, el problema de la "compañía". Ya por primera vez se enuncia en Nebrija la asociación que toma de Valla. Todo ello demuestra que Nebrija no procura una renovación. Pero sí una depuración. Pues no es el que emplea un vocabulario ajeno a la escolástica. Sí representa un agregado (en su específica modulación humanista-hispana) a ésta. Se cifra así también la utilidad del latín en el régimen total del saber, y en sus centros o facultades superiores: Teología, Jurisprudencia, Medicina.

Junto a ello, la denuncia de un déficit propio. Ante el mando de la reina, él confiesa su perplejidad. "Quiero agora confessar mi error, que, luego en el comienço, no me pareció materia en que io pudiesse ganar mucha honra, por ser nuestra lengua tan pobre de palabras, que por ventura no podría representar todo lo que contiene el artificio del latín" ${ }^{43}$. Artificio del latín es una redundancia. Frente a la pobreza de "nuestra lengua" (antes dijo "lengua castellana"), la copia del latín. El valor de la abundancia es un valor de retórica.

No habrá más mando por parte de la reina. Pero la operación próxima está aquí encerrada. Se expone aquí una gramática del latín. Ello es gramática de la gramática. Conviene no sólo conocer ésta, sino también elevar el romance. Según su canon latino. Ya no habrá gramática de gramática, sino gramática sobre la lengua castellana. Otros textos, sin embargo, la prefiguran. Prefiguran su léxico. Y no sólo. También sus conceptos, y su propia relación con los tiempos. Poco antes del Nebrija de 1481, en prólogo a sus Poesías, Lorenzo de Médici abundaba en las cuestiones de reputación de lengua. Así, decía,

\footnotetext{
Ibidem, pp. 200-201.

${ }^{41}$ Ibidem, p. 201.

42 Idem.

43 Ibidem, p. 202.
} 
propio de la elevación de la lengua latina a universal no fue sólo su aptitud endógena, sino también el curso político de las cosas del mundo: esta extroversión imperial era la que hacía a la lengua "non solamente comune per tutto il mundo, ma quasi necessaria"44. Así se expresa la continuidad latín - italiano, y el florecimiento de éste, precisamente por virtud del "successo e augumento al fiorentino imperio" $"$. Y no al contrario.

Esta relación de compañía, inversa a la postulada por Valla, la trae expresa por primera vez en romance castellano Gonzalo García de Santamaría. Jurista aragonés, de familia de conversos, anexo a los Trastámara. En su prólogo a las Vidas de los santos religiosos de San Jerónimo (ca. 1491) da cuenta de ello. Tema o problema del texto comienza siendo el de la traducibilidad. Y ello en relación con un trabajo previo de García de Santamaría: su versión al latín de los evangelios. Se ocupa ahora del género de las vita patrum. De tal versión anterior, dice García de Santamaría que la hizo "poco ha"46. De ahí saca su comentador que el prólogo a San Jerónimo ha de ser de entre 1486-1491. Se ocupa en el prólogo de problema de estilo. Y así, dice: "E porque el real imperio que hoy tenemos es castellano, y los muy excelentes rey e reyna nuestros senyores han escogido como por asiento e silla de todos sus reynos el reyno de Castilla, deliberé poner la obra presente en lengua castellana. Porque la fabla comúnmente, más que otras cosas, sigue al imperio" ${ }^{\text {"47 }}$. No es, pues, primero el idioma castellano, en el orden de estas relaciones. Es, en efecto, segundo, es secundum, le sigue, sequitur. Castellano, sin embargo, es el imperio dicho, o al menos su asiento o silla. El Reino de Castilla se presenta como espacio de decisión de la Monarquía. Por lo demás, "todos los reinos" son sólo unidad de agregación. Luego de prevalencia política viene, como consecuencia, compañía de lengua. Y seguimiento. Tal imperio, primero dicho "castellano", indica sólo, según dependencia de terminología latina, edificio político en planta regia. No alude a dominación en gran extensión. Refiere condición de majestad, forma magistral, magisterio en el ejercicio del poder. Imperio dice una magistratura. Significa función pública en capacidad de mando. No se es emperador: se tiene imperio. Y regio alude a la condición dinástica en título, etc. Todavía, pues, nada de Indias. Nada de América puede saberse. Tampoco podrá saberse en el propio texto de 1492. Nada pues de imperio en aquel sentido perdurado. De este imperio en república, Castilla es fundamento. Es fundación y fundamentación. Sigue a ésta su propia lengua: se usa el tecnicismo, no se alude ya a romance.

García de Santamaría postula este seguimiento o consecución en términos muy estrictos. "E quiando los príncipes que reynan tienen muy esmerada e perfecta la fabla, los súbditos esso mismo la tienen. E quando son bárbaros e muy ajenos de la propiedad del fablar, por buena que sea la lengua de los vasallos e subjugados, por discurso de luengo tiempo se faze como la del

\footnotetext{
44 L. de Médici, Comento dei miei sonetti, Florencia, Olschki Editore, 1991, p. 149

45 Idem.

46 G. García de Santamaría, Las vidas de los sanctos religiosos de Egipto, Zaragoza, Hurus, ca. 1488, fol. 1r.

47 Idem.
}

imperio" ${ }^{48}$. Si éste es constante, nada se opone a su hegemonía en cuanto a estilo y lengua. El imperio acompaña al tiempo. Con él, su lengua se reproduce. Ello atañe a una antropología. Una teoría de la maleabilidad del hombre no en cuanto a su núcleo, sino en cuanto a su segunda naturaleza. La lengua es también uso. Forja costumbre. Puede ser acostumbrada. El uso es asimismo parte del derecho. Pero otro tipo de usos advienen en su texto. Fundamentalmente domésticos u oiconómicos, siquiera en cuanto a la metáfora. "Ca el vocablo deve ser como la moneda... que en ninguna tierra de las mismas del príncipe que la batió se rehuse"49. Tierra, podría ser única. Pero territorio, uno no lo había en la Monarquía compuesta. Máxime en tal momento de itinerancia de corte. De plural recorrido de curia. De ahí la necesaria dificultad para la elección de su moneda-lengua. Y la confusión ante la que esta decisión se ejercía. Sólo ahora, en efecto, comienza a realizarse. Este es testimonio. Se requiere, pues, de cuño reconocido en la moneda. En ello estriba la legitimidad del mando. Así también con la lengua. Si no hay reconocimiento, no cabe obediencia. Cuño de la lengua, eso es la gramática. Una lengua es elevada, pues, a norma: "piedra de toque de todas las otras lenguas de la tierra" $"$.

De esta operación se hace cargo el casi último texto. El a todos los efectos definitivo. Pero evidencia cómo el romance-vulgar no puede ser norma alguna, bien que disponga de aptitudes propias. La gramática le es externa. Le es anterior y prevalente. No sólo a escala de normas. También en el orden del tiempo. Por eso su autor se inicia en el latín y pasa al castellano. Por eso Nebrija titula a su texto Gramática sobre la lengua castellana (1492). Es, en efecto, un cuño. Una horma. Una imposición. Reducción a forma cierta. Siendo la lengua vernácula desatada, impone arte. Es una operación, con toda la materialidad que ello comporta. En cuanto tal, alguna justificación le es necesaria. Reorganiza los fragmentos hasta ahora manejados. Veámosla.

La antología que reproduce el texto lo hace como Gramática de la lengua castellana. No es así. Conocemos la razón. Se abre sin embargo su prólogo conforme a una misma salutación institucional, análoga en 1492 a la dada en 1487. "A la mui alta \& assí esclarecida princesa doña Isabel, la tercera deste nombre, Reina y señora natural de España \& la nislas de Nuestro Mar. Comiença la Gramática que nueva mente hizo el maestro Antonio de Lebrixa sobre la Lengua Castellana. \& pone primero el prólogo" "51. El prólogo es la motivación. Pero este saludo en cierta medida la supone. O la integra, así en cuanto ausencia. En efecto, junto a su estatuto constitucional indiciario, ya comentado a propósito de 1481, y aquí mantenido íntegramente, coexiste una diferencia. Esta diferencia es una ausencia. En la anterior salutación, se refería el mandado de la reina. Aquí ya no lo hay. Ello es índice de la sobreexposición y desprotección del texto en cuanto a los motivos. Tanto más Nebrija ha de darlos.

\footnotetext{
Idem.

49 Idem.

50 Idem.

51 Nebrija, Gramática sobre la lengua castellana, Madrid, RAE-Galaxia Gutenberg, 2011, p. 93.
} 
Y ellos son novedad. Bien que guardada en viejos odres. Los hemos visto. Venimos viéndolos.

Aquí va el primero: "Cuando bien conmigo pienso". Aquí está Valla. ¿Sigue luego estándolo? "Cuando bien conmigo pienso, mui esclarecida Reina, i pongo delante los ojos el antigüedad de todas las cosas que para nuestra recordación \& memoria quedaron escriptas, una cosa hallo e saco por conclusión mui cierta: que siempre la lengua fue compañera del imperio; \& de tal manera lo siguió, que junta mente començaron, crecieron \& florecieron, \& después junta fue la caída de entrambos" ${ }^{52}$. He ahí la gloria de Valla. Allí mismo también su destrucción. Comienza, pues, una operación típicamente humanista, tal y como aquél la realizó. Una operación de regreso y atención, en texto y restos, a las "antigüedades", así fundamentalmente a las "escriptas". Frente a la moralización típica de la historia, en su ejemplaridad, el humanismo lleva trato con el texto. De ahí extracta la conclusión: que, en efecto, "siempre fue la lengua compañera del imperio". Ello es Valla. A la vez, también Lorenzo. Y García de Santamaría. Pues, se dice, "de tal manera le siguió" que su suerte fue idéntica. Primero el imperio. Con él la lengua, siempre compañera suya, también en la caída.

Hay luego enumeración de monarquías, según las exigencias proféticas del libro de Daniel. Se ocupa en quinto lugar de hebreos, siguiendo el género de antigüedades judías. Se habla de su caso, su génesis y éxodo. Su constante mezcla, colisión, contigüidad, traducción de lenguas. Desde este mixtum, su "hazer por sí mesmos cuerpo de gente" ${ }^{53}$. Y a su estricto desmembramiento político, también descomposición de lengua. Hay luego ejemplo de griegos. Y de cómo su lengua floreciente "creció $[\ldots]$ hasta la monarchía" ${ }^{4}$. Su caída naturalmente viene del "desatar los reinos \& repúblicas de Grecia, $\&$ los romanos se hizieron señores della [s. mío]"55. Luego, Roma. De ella, su decline and fall. Todos son ejemplos existencialmente consumados. Nebrija habla de lo que vive la vis de su expansión, su autoridad o auge. "Lo que diximos de la lengua ebraica, griega \& latina, podemos mui más clara mente mostrar en la castellana" ${ }^{56}$. Inmediatamente antes mencionó la lengua arábiga. Luego la castellana hace, de nuevo, la quinta. Como lo hizo la hebrea en la antigüedad. Se reproduce un patrón. Se cierra un ciclo. Se abre tiempo de arte de paz. De ahí la necesidad de la gramática sobre la lengua. Se refleja un proceso histórico político (lo que laxamente podemos llamar constitucional). Se destaca el gobierno de un conjunto de partes por una sola. Lo que llamamos imperio, mejor llamarlo Monarquía: gobierno de todos por uno. Se llega así al llamado tiempo de paz, para Nebrija presente: "en la fortuna \& buena dicha de la cual, los miembros \& pedaços de España, que estaban por muchas partes derramados, se reduxeron \& aiuntaron en un cuerpo \& unidad de Reino, la forma \& travazón del cual, assí está ordenada, que muchos siglos, injuria \& tiempos no la podrán romper ni desatar" 57 . Ello sabemos que no es así. No hubo unidad de Reino, sino composición de Monarquía. Sí ayuntamiento de partes. Unión, pues, no dice unificación.

Constantemente se refiere el problema de la compañía. Problema de valor central a propósito de jurisdicción. Después, se dice, "de la justicia \& essecución de las leies que nos aiuntan \& hacen vivir igual mente en esta gran compañía, que llamamos reino \& república de Castilla; no queda ia otra cosa sino que florezcan las artes de la paz" ${ }^{158}$. Justicia, dice, no legislación. Pese a la ditología, no todo era Castilla. Tampoco menciona derecho ni derechos. Pero ello indica la centralidad que cobraba el impulso de introducción de la jurisdicción castellana en otros territorios. Los cuales se resistían. Hasta mucho más tarde lo hicieron. Ello era sólo un conato, una pulsión. Nebrija sin embargo eleva Castilla a cabeza de cuerpo de Monarquía. Pero cabeza no es totalidad de cuerpo. Luego dirá por qué. Pero antes hay otras cosas. Dichas artes de paz, por ejemplo. Entre las primeras, dice, es aquella que enseña arte de lengua. Está, en efecto, la gramática. Sólo la supera, en su orden, la contemplación, propia del entendimiento. La gramática enseña la lengua. "Esta hasta nuestra edad anduvo suelta \& fuera de regla" ${ }^{59}$. De ahí la exigencia de cuño, la necesidad de que sea ahormada. De imponer brida a la lengua desbocada. Interviene en occasio de fortuna: "Lo cual hezimos en el tiempo mas oportuno que nunca fue hasta aquí, por estar ia nuestra lengua tanto en la cumbre, que más se puede temer el decendimiento della que esperar la subida" ${ }^{\prime 60}$.

Ante esta circunstancia, un primer provecho es fijar la lengua para facilitar la crónica. Otro segundo, exponer el acceso al estudio del latín. Uno tercero, procurar la conquista de pueblos de lengua diversa, según la imposición de la lengua castellana, y así también sus usos y leyes. Ante ello, decidió Nebrija "sacar la novedad desta mi obra de la sombra \& tinieblas escolásticas a la luz de vuestra corte, a ninguno más justamente pude consagrar este trabajo que a aquella en cuia mano \& poder, no menos está el momento de la lengua que el arbitrio de todas nuestras cosas" ${ }^{\prime 61}$. La centralidad política de la Corte se hace así explícita, también en cuanto al desenvolvimiento de la lengua. Desde Alonso de Cartagena, se cierra el círculo. Ella es el núcleo de decisión de la Monarquía. Sólo en Castilla había exclusiva centralidad de Corte: Cortes en Valencia, Aragón, etc. Juntas en Vizcaya o Navarra. En Castilla, también Cortes urbanas, pero no con representación nobiliaria. Hay, en efecto, en Castilla, o en la Corte castellana, la centralidad del momento de la lengua. Así su vis o impulso. Lo que, en cuanto a tal momento, descansaba en Valla en la latinitas, lo hace en Nebrija en la voluntad de la Reina.

Sobre esta experiencia, marcando una diferencia respecto de ella, Juan de Valdés escribió su Diálogo de la lengua. Hecho desde Nápoles, en 1535, restó

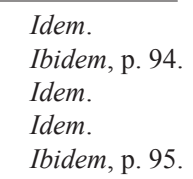

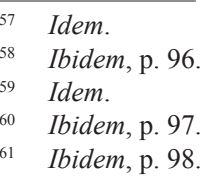


inédito hasta la intervención y edición del texto por parte de Mayans, en 1737. Ello es la oclusión del tracto de secuencias. Pero caben momentos intermedios. Por de pronto, este propio texto. El Diálogo se presenta efectivamente como un diálogo o discusión entre Valdés y otros interlocutores, ellos italianos. Un primer fragmento posible acuerda con Nebrija: "tantas diferencias ay de lenguas, quanta diversidad de señores" ${ }^{62}$. Pero esta pluralidad no es aislamiento. Ya se sabe: si hay límite, también hay comunicación. Ella es la que forja diferenciación. Y ello no sólo en lo que atañe a cuestiones de lengua. También en lo referente a moral, derecho, política: "esto no solamente en el hablar, pero aun también en el conversar y en las costumbres" $" 63$.

Hasta en la cabeza pretendida de España hubo fracción, diferenciación, proliferación de límite: “aun hasta Castilla estuvo dividida" ${ }^{64}$. Ejerce una memoria reciente de ochocientos años de historia. Se hace luego la historia política de división y asociación entre los reinos. Se señala, a la altura de la fecha dicha, la especificidad de Navarra y Granada: "debaxo de la corona de Castilla" ${ }^{65}$, no en ella. Hay en suma miembros diversos, entonces ayuntados, según la metafórica anteriormente manifestada, en ese cuerpo o corporación de Monarquía. No hay, sin embargo, aunque lo pretenda, "corona de Spaña"66. En cualquier caso, el diagnóstico está hecho: "La qual diversidad de señoríos pienso yo que en alguna manera aya causado la diferencia de las lenguas, bien que cualquiera dellas se conforma más con la lengua castellana que con ninguna otra" ${ }^{67}$. Como en García de Santamaría, como en Nebrija, hay compañía, acompañamiento de lengua, por seguimiento o consecuencia de la actividad política. Es esta conformidad y generalidad de la lengua castellana la que produce división y pluralidad aun en su propio seno, ayuntándose con el léxico privativo de cada territorio. Uno de los interlocutores, sin embargo, realiza una pregunta, y así ordena la diversidad: la centra o jerarquiza. "Nos os queremos meter en ese labirinto; solamente, como a hombre criado en el reino de Toledo y en la corte de Spaña, os preguntaremos de la lengua que se usa en la corte" ${ }^{68}$. Retomamos, pues, la evidencia de Alfonso de Cartagena. También la últimamente notada por Nebrija. Carlos V hizo de Toledo centro del sistema político. Felipe II enriquecerá o hará complejo dicho centro toledano: lo multiplicará en forma triangular. Hará de Toledo el centro político, de Madrid, el núcleo administrativo. Y de El Escorial el complejo religioso. Pero la pregunta por la corte es pronto eludida.

No obstante, una diferencia capital emerge luego en el texto. Allí la afinidad con Nebrija es destruida. En efecto, Valdés es preguntado por la lectura de

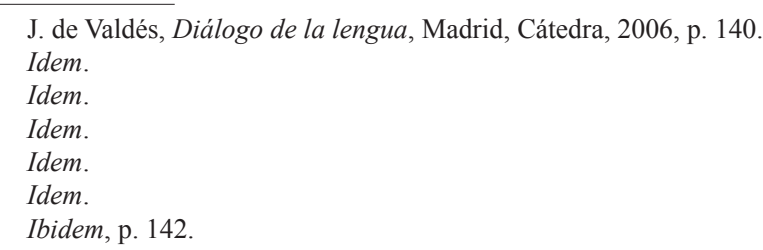

su "Arte de Gramática Castellana"69. Éste responde no haberla leído. Le preguntan por qué. Se justifica: "nunca pensçe tener necesidad dél, y porque nunca lo he oído alabar; y en esto podéis ver cómo fue recibido y cómo era provechoso que, según entiendo, no fue imprimido más que una vez" ${ }^{70}$. Se pretenda política o no, Nebrija es un outsider. Su última operación, incomprensible. Valdés se sitúa en otro espacio.

Y este espacio no está sobredeterminado por la presión normativa del latín. Otra forma de operar autónoma en cuanto a lengua y arte de lengua se consolida ya en Valdés. Dice: "esto lo hago con perdón de la lengua latina, porque quando me pongo a escribir en castellano no es mi intento conformarme con el latín, sino explicar el conceto de mi ánimo"71. Este es el centro del diálogo. Primero, la justificación de Valdés, límpida en términos jurídicos de intentio fundata. Segundo, su pulsión de independencia respecto el canon de (la) gramática. Ello es un índice, también un factor. Ya no gobierna el latín la producción del mejor castellano. Lo hace, en relación con lo dicho antes, el ingenio cortesado-curial de Toledo. Ello, el ingenio, dice referencia al ánimo. También el recurso al conceto. Ambas categorías tendrán porvenir. También debido a su desvinculación de la norma latina, a su independencia de la excelencia italiana. Fundarán una lengua en literatura propia. Al tiempo, supondrán, en su exceso, la cancelación de toda política posible. Llevarán al extremo la relación literatura / política, lengua / imperio. Harán de ella contradicción. Ello es lo barroco, o lo será. Será el exceso en desequilibrio de ingenio.

Se aclara luego. Uno de los interlocutores pregunta: "Dezidme, por vuestra fe, aunque sea fuera de propósito, ¿qué diferencia hazéis entre ingenio y juicio?"72. A lo que Valdés replica: "El ingenio halla qué decir, y el juicio escoge lo mejor de lo que el ingenio halla, y pónelo en el lugar que ha de star; de manera que de las dos partes del orador, que son invención y disposición (que quiere decir ordenación), la primera se puede atribuir al ingenio, y la segunda al juicio"73. Inventio / dispositio han de quedar, pues, concordadas. Exceso de una es carencia de otra. Son dos complementarios dispositivos retóricos. Han de construir un equilibrio. Ello es código de excelencia. No es el rumbo que tomará el lenguaje literario hispano. Habrá acumulación de inventio sin distinción. La falta de discriminación (orden) provocará crisis de lengua. El inmediato hallazgo de la literatura del Siglo de Oro será la producción de tal desequilibrio.

A cien años de distancia, un discurso, otro, el Discurso poético de Jáuregui, parece hacerse cargo del devenir del diagnóstico de Valdés. No quiero decir que ejerciera una referencia intencionada. Sólo que las categorías que discute, respecto de $s u$ presente, ciertamente otro que el de Valdés, son to-

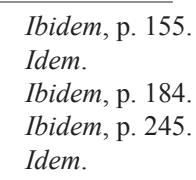


davía las mismas. Son las mismas, pero en cuanto se trae noticia de su invalidez, a causa del desequilibrio dicho. Antes dice que quienes creen que enriquecen la lengua, quienes pretenden así construir su copia, en verdad la descomponen. Son los que luego llama movidos por "un aliento y espíritu de ostentarse bizarros y grandes" $" 74$. Ello es en cierta medida una vis de dignidad. Pero yerran en los medios. Arruinan su pulsión, lo hacen por desembridado exceso. Por carencia de norma. Hace mucho que el latín aquí no juega. O no en el sentido previo. Es tiempo de dominio artístico total del vernáculo. Se pretende, de hecho, el castellano anterior al latín. Castilla está más cerca de Roma que ésta de sí misma. Ello hace de los ejercicios de tales poetas "no en parte alguna útiles, antes en extremo dañosos a nuestra lengua y patria"75. La vieja asociación entre literatura y política, entre lengua e imperio, emerge aquí de nuevo. Pero lo hace para traer noticia de su extrema torsión o violencia. La lengua no acompaña la política. Se ha invertido su relación. La lengua se tuerce sobre sí misma, metáfora sobre metáfora, ingenio sobre ingenio. Se hace así inservible a la política de patria. Se hace de hecho en todo punto inaccesible. La lengua se descompone. "Nuestra lengua": ni siquiera la menta. Es evidente de qué habla. Es la experiencia de su tiempo. En su inutilidad, produce tal descomposición en el gobierno del cuerpo de Monarquía.

No hay señorío sobre la lengua, es imposible su sujeción o dominio. "Así vienen a ser, por esta flaqueza, siervos y esclavos de la locución que los desavía y los arrastra por donde quiere, habiendo de ser dueños y señores para servirse della con magisterio"76. La misma inversión de la relación literatura / política se produce a escala del poeta y su obra. No hay control posible. "Los poetas que decimos, en vez de tenerlas debajo de la pluma, las tienen encima de la cabeza y están de manera gravados, que no aciertan a dar un paso sino por donde imperan las palabras a cuya potestad se entregaron"77. Gravados: sigue usándose el término jurídico, en cuanto político, para hablar de lengua. Y es que se hace evidente que es ahora ésta quien detenta imperio. Se presenta así indisponible a la voluntad, individual y política. Es de suyo, a estas alturas, sólo una constante conmoción. La lengua ha superpuesto el ingenio al juicio. Es ingobernable. En ella no hay ya utilidad, tampoco comprensión: sólo impacto.

Un Arte de la lengua española castellana (que evidencia, por lo demás, la todavía necesidad del adjetivo) de mismo momento trae noticia de ello. Es ciertamente una gramática. Tradicionalmente, éstas terminaban en una retórica. En cuanto a figuras, incorpora cientos en masa o secuencia de vértigo. Éstas se expandían sin orden por el gran espacio de la catolicidad. Una gramática, o, mejor, la primera Gramá-

\footnotetext{
74 J. de Jáuregui, Discurso poético, edición online Observatoire de la vie littéraire, 2016: http://obvil.sorbonne-universite.site/corpus/gongora/1624_discurso-poetico/.

75 Idem.

76 Idem.

77 Idem.
}

tica de la única Real Academia de la Lengua, titulada Gramática de la lengua castellana, dada a la luz en 1771 , incorpora todavía un cierre en retórica. Va tras la sintaxis, construcción general. Retórica es construcción figurada. El habla figurada se ha recortado. Ha sido reducida. La Gramática, sí, resuelve en retórica. Pero sólo cuatro figuras son recogidas y normalizadas. Sólo cuatro. Repito: sólo cuatro. Hipérbaton, elípsis, pleonasmo, silépsis. Al cabo de la secuencia, sólo eso: eso es todo.

\section{Alba de Nación: índice de ausencias}

Ha mediado cambio. Ha advenido nueva dinastía. Nueva organización de la totalidad de la Monarquía se ha pretendido. Se ha procurado destruir su constitución católica. Ha querido hacerse de ésta un imperio (empire), ahora sí, sólo comercial. Operación crucial en esta reconstrucción, en esta política de reforma, era desde luego ordenar el discurso. No en cuanto a sus contenidos. Sí, en cuanto éstos fueran sólo su forma. La lengua barroca no buscaba comprensión. Comunicación, por tanto, tampoco. Ello era un obstáculo: obstrucción de circulación. Orden al exceso debía imponerse, si quería facilitarse el tránsito de materia y mercancía. Se imponía el juicio. Se acrecía el cálculo. Se destruía el ingenio. Alguien patrocinó sus exequias.

Al margen de la lengua, no sólo la economía era política. Nuevas formas de construcción de ésta también fueron sucediéndose. Reparemos en la fecha: 1771. Está cercano el momento de independencia anglo-americano. Está cerca, pues, el momento revolucionario francés. Allí está Grégoire. Hay, entonces, próxima constitución de nación. También en el caso hispánico. O, cabe decir, ahora, en el caso español. Ello es 1812. Luego vendrá 1833, con su experiencia de dicho lapso, y su reorganización del territorio. Y producción perdurada de convulsión política por discusión espacial. En efecto, reducir reinos a provincias implica trauma, también en cuanto a políticas de lengua. Pero la decisión de esta operación la trae un momento previo. Es el ya dicho: 1812 . No porque sea Constitución moderna: no lo es, o no es asequible al canon franco-USAmericano. En 1812 abunda lo español. Ello, es sabido, comporta estrictas exclusiones ${ }^{78}$. También en cuanto a lengua. Se habla del sujeto español. Se habla de los españoles. No se habla de su lengua. Ésta se da ya por supuesta. Ya se sabe cuál es. Ya es evidente de qué se habla. Conoce 1812, pues, un estatuto híbrido. Sobre la matriz jurisdiccional de su texto se construye nación. También, pues, en cuanto a lengua: la nación española que habla español. Ello constituye una decisión, no tematizada en el texto. Pero es una decisión política. Funda nuevas discriminaciones.

Cf. B. Clavero, "Cádiz 1812: Antropología e Historiografía del Individuo como Sujeto de Constitución”, en J. Pardos (ed.), Constitucionalismo colonial. Oeconomía de Europa, Constitución de Cádiz y más acá, Campus de Cantoblanco, Ediciones Universidad Autónoma de Madrid, 2016, pp. 165-262. 


\section{Bibliografía}

de Cartagena, A., "Sigue el libro de Alfonso, obispo de Burgos", en T. González, A. Moreno, P. Saquero (eds.), Humanismo y teoría de la traducción en España e Italia en la primera mitad del siglo XV, Madrid, Clásicas, 2000, pp. $194-264$.

Clavero, B., Antidora. Antropología católica de la economía moderna, Milano, Giuffrè Editore, 1991.

-, “Cádiz 1812: Antropología e Historiografía del Individuo como Sujeto de Constitución”, en J. Pardos (ed.), Constitucionalismo colonial. Oeconomía de Europa, Constitución de Cádiz y más acá, Madrid, Campus de Cantoblanco, Ediciones Universidad Autónoma de Madrid, 2016, pp. 165-262.

de Covarrubias, S., Tesoro de la lengua castellana o española, Madrid, Luis Sanchez, 1611.

Curtius, E., Literatura europea y Edad Media latina. 1, Madrid, FCE-España, 1999.

-, Literatura europea y Edad Media latina. 2, Madrid, FCE-España, 1999.

Duque, F., El sitio de la historia, Madrid, Akal, 1995.

-, "La lógica de la constitución / La constitución de la lógica", en J.A. Pardos et. al. (eds.), Historia en fragmentos. Estudios en homenaje a Pablo Fernández Albaladejo, Madrid, UAM Ediciones, 2017, pp. 833-846.

Fernández Albaladejo, P., "Entre la «gravedad» y la «religión». Montesquieu y la «tutela» de la monarquía católica en el primer setecientos", en Materia de España. Cultura política e identidad en la España moderna, Madrid, Marcial Pons, 2007, pp. 149-176.

García de Santamaría, G., Las vidas de los sanctos religiosos de Egipto, Zaragoza, Hurus, ca. 1488, fol. 1r.

Grégoire, H., "Rapport sur la nécessité et les moyens d'anéantir les patois et d'universaliser1'usage de la langue française", en D. Julia, J. Revel y M. de Certeau (eds.), Une politique de la langue. La Révolution française et les patois: l'enquête de Grégoire, Paris, Gallimard, 2002, pp. 300-317.

de Jáuregui, J., Discurso poético, edición online Observatoire de la vie littéraire, 2016: http://obvil.sorbonne-universite.site/ corpus/gongora/1624_discurso-poetico/.

Klemperer, V., LTI. La lēngua del Tercer Reich. Apuntes de un filólogo, Barcelona, Minúscula, 2001.

López Rodríguez, C., “¿Constitución de Nación, perdurado Imperio? Todavía Monarquía. Políticas de la reflexión en el primer constitucionalismo español”, Eikasia: revista de filosofía 83, 2018, pp. 29-65.

-, Economía de la gracia. Constitución de Monarquía. Integración de Trento. Extraño caso católico, Cantoblanco, Ediciones de la Universidad Autónoma de Madrid, 2020, disponible en: https://libros.uam.es/?press=tfm\&page=catalog\&op=view\&pa th $\% 5 \mathrm{~B} \% 5 \mathrm{D}=928 \&$ path $\% 5 \mathrm{~B} \% 5 \mathrm{D}=1649 \&$ path $\% 5 \mathrm{~B} \% 5 \mathrm{D}=1632-1$.

de Médici, L., Comento dei miei sonetti, Florencia, Olschki Editore, 1991.

de Nebrija, A., Introductiones latinae, en "Paginae Nebrissenses", Gramática sobre la lengua castellana, Madrid, RAE-Galaxia Gutenberg, 2011, pp. 175-343.

-, Introduciones latinas, en "Paginae Nebrissenses", Gramática sobre la lengua castellana, Madrid, RAE-Galaxia Gutenberg, 2011, pp. 175-343.

-, Gramática sobre la lengua castellana, Madrid, RAE-Galaxia Gutenberg, 2011.

Sánchez Ferlosio, R., "Carácter y destino", Claves de la Razón Práctica 153, 2005, pp. 4-12.

Schmitt, C., Teoría de la Constitución, Madrid, Alianza, 2016.

de Troyes, Ch., Cligés, Madrid, Alianza, 1993.

de Valdés, J., Diálogo de la lengua, Madrid, Cátedra, 2006.

Valla, L., De linguae latinae elegantia, Cáceres, Universidad de Extremadura, 1999.

Vélez, F., "Desflorada lengua (Entrada a la LMH)", Despalabro. Ensayos de humanidades 4, 2010, S 115-S 119.

-, "Translatio studiorum: Breve historia de la transmisión de los saberes", Mutatis Mutandis. Vol. 6, No. 1. 2013, pp. 126-138.

-, “«Translatio imperii». Del mar de Dante al océano de Vázquez de Menchaca”, Revista de Estudios Histórico-Jurídicos XXXV, 2013, pp. 783-797.

Villacañas, J. L., "Epílogo. La nación tardia y nosotros. El sentido de un concepto”, en H. Plessner, La nación tardía, Madrid, Biblioteca Nueva, 2017, pp. 209-238. 